\title{
Surfactant therapy for meconium aspiration syndrome in Dr. Soetomo General Hospital - A case series
}

\author{
Authors: M. R. D. Mustakim ${ }^{1,2}$; M. T. Utomo ${ }^{1,2, *}$; R. Etika ${ }^{1,2}$; D. Angelika ${ }^{1,2}$; K. D. Handayani ${ }^{1,2}$; T. Y. \\ Aden $^{1,2}$
}

Affiliations: ${ }^{1}$ Department of Child Health, Faculty of Medicine Universitas Airlangga, Dr. Soetomo Hospital, Surabaya, Indonesia; ' Dr. Soetomo Hospital, Surabaya, Indonesia

\begin{abstract}
INTRODUCTION: Meconium staining of amniotic fluid (MSAF) is a natural phenomenon in pregnant mothers and their fetuses. MSAF may lead to developing Meconium Aspiration Syndrome (MAS). Surfactant replacement therapy has recently emerged as a therapy in MAS, but no guideline outlines how to administer it properly.
\end{abstract}

CASE PRESENTATION: We present two term neonates with severe MAS cases focusing on the bolus surfactant replacement therapy. The first baby was given surfactant at 23 hours after birth and the second baby at 8 hours after birth. We used Survanta (beractant) in the dose of 100 $\mathrm{mg} / \mathrm{kg}$ BW in both cases. Clinical improvement was observed 24 hours after surfactant bolus administration with different clinical characteristics, treatment approaches, and outcomes.

CONCLUSION: In conclusion, therapeutic surfactant bolus in severe MAS may improve outcomes without significant adverse side effects.

Keyword: Meconium Aspiration Syndrome, Surfactant, Persistent Fetal Circulation Syndrome, Case report

\section{INTRODUCTION}

Meconium-stained amniotic fluid (MSAF) is a natural phenomenon occurring in pregnant mothers and their fetuses. The presence of MSAF may lead to developing Meconium Aspiration Syndrome (MAS). This syndrome is characterized by hypoxia, hypercapnia, and acidosis [1]. Onethird of infants with MAS require intubation and mechanical ventilation. Data from Dr. Soetomo Hospital, where our study was conducted, revealed that MAS contributed was the 7th top leading neonatal death cause, with $2.3 \%$ of all total death [2]. Surfactant is composed of phospholipids and associated proteins produced by the type II pneumocytes that line the alveoli and smallest bronchioles [3]. Surfactant replacement has recently emerged as a therapy. It is administered intratracheally as either a bolus dose or in dilute form to lavage the lungs in neonates with MAS. However, no guideline outlines how to administer bolus surfactant therapy in MAS in our region. It is still controversial between bolus and lavage surfactant therapy administration. Limited study has directly compared these two treatment modalities with different clinical outcomes. We reported two patients with severe meconium aspiration syndrome treated at Dr.

\footnotetext{
*Corresponding author: Martono Tri Utomo, Department of Child Health, Faculty of Medicine Universitas Airlangga, Dr. Soetomo Hospital, Surabaya, Indonesia. Email: mrmartono73@gmail.com; Potential Conflicts of Interest (Col): All authors: no potential conflicts of interest disclosed; Funding: All authors: no funding was sought; Academic Integrity. All authors confirm that they have made substantial academic contributions to this manuscript as defined by the ICMJE; Ethics of human subject participation: The study was approved by the local Institutional Review Board. Informed consent was sought and gained where applicable; Originality: All authors: this manuscript is original has not been published elsewhere; Review: This manuscript was peer-reviewed by three reviewers in a double-blind review process; Type-editor: Shazaib (UK)
}

Received: $19^{\text {th }}$ March 2021; Initial decision given: $19^{\text {th }}$ June 2021; Revised manuscript received: $02^{\text {nd }}$ August 2021; Accepted: $09^{\text {th }}$ November 2021. Copyright: (C) The Author(s). This is an Open Access article distributed under the terms of the Creative Commons Attribution License (CC BY-NC-ND) (click here) which permits unrestricted use, distribution, and reproduction in any medium, provided the original work is properly cited. Publisher: Rwanda Biomedical Centre (RBC)/Rwanda Health Communication Center, P. O. Box 4586, Kigali. ISSN: 2079-097X (print); 2410-8626 (online)

Citation for this article: M. R. D. Mustakim; M. T. Utomo; R. Etika et al. Surfactant therapy for meconium aspiration syndrome in Dr. Soetomo General Hospital: A case series. Rwanda Medical Journal, Vol. 78, no. 4, p. 5-11, 2021. https://dx.doi.org/10.4314/rmi.v78i4.1 
Soetomo General Hospital, Surabaya, Indonesia, with different clinical characteristics, treatment approaches, and outcomes. We emphasize surfactant bolus treatment and the treatment outcomes. We aim to improve prognosis, increase survival, and MAS prevention, benefiting the patient and public health.

\section{CASE PRESENTATION}

Case 1: A baby girl with a chief complaint of dyspnea and desaturation one day before hospital admission. She was delivered by the caesarian section with fetal distress and premature rupture of the membrane (PROM). Mother was 25 years old. No history of pregnancy problems. The gestational age was 39-40 weeks; the birth weight was 3000 grams, $50 \mathrm{~cm}$ in length, and $34 \mathrm{~cm}$ in head circumference. Skin, nails, and umbilical cord were stained with greenish meconium. The Apgar Score was 3 at one minute and 4 at five minutes. The baby was not crying, grunting, and had poor muscle tone. We did the initial step, including warm and maintaining normal temperature, airway position, tactile stimulation, suction, and repositioning. We continue with nasal Continuous Positive Airway Pressure Therapy (CPAP) with Positive end-expiratory pressure (PEEP) 8 and maximum $\mathrm{FiO} 2$ 80\%.

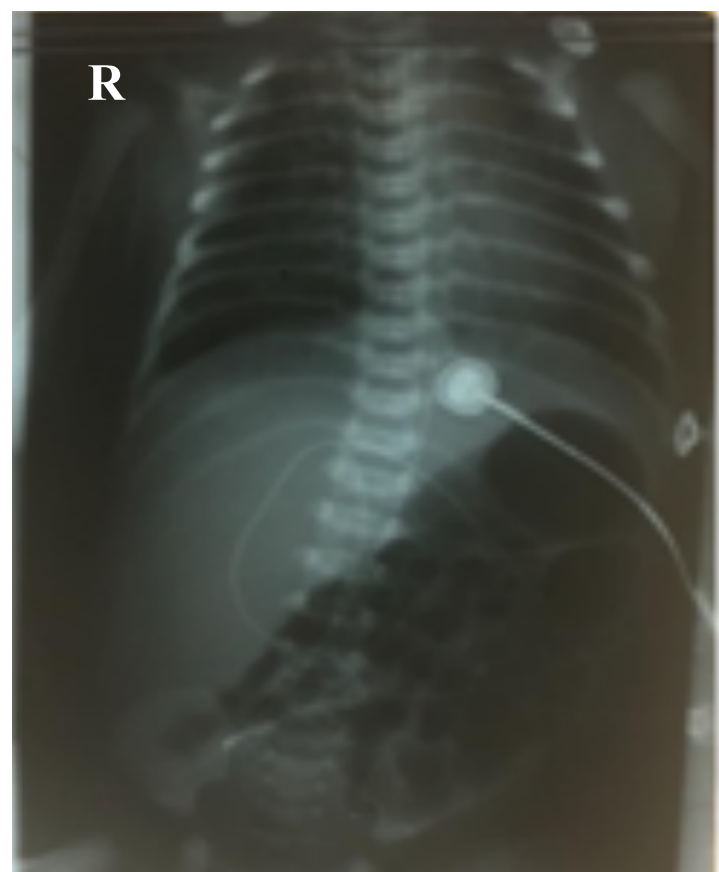

Physical examination on admission revealed a weak cry with minimal grimacing to a painful stimulus, grunting, and peripheral cyanotic. Blood pressure (BP) was 65/40 mmHg, heart rate was 180 beats per minute, respiratory rate (RR) 70 breaths per minute with the temperature was 36,5oC, pre ductal saturation was $81 \%$ room air, and post ductal saturation was $74 \%$. Capillary refill time was less than 3 seconds. Downes score was 5 . Chest $X$-Ray showed an area of diffuse hyperinflation. Decreased expansion of the lung was indicated by diaphragm linear that appeared as high as the 10th chest rib. Blood gas analysis (BGA) revealed metabolic acidosis with the value: $\mathrm{pH} 7.25, \mathrm{pCO} 2$ of $40 \mathrm{mmHg}, \mathrm{pO} 2$ of $104 \mathrm{mmHg}, \mathrm{HCO} 3$ of 17.5 $\mathrm{mmol} / \mathrm{L}, \mathrm{TCO} 2$ of $18.7 \mathrm{mmol} / \mathrm{L}, \mathrm{BE}$ of $-9.7 \mathrm{mmol} / \mathrm{L}$, SO2 of $97 \%$. Echocardiography revealed severe tricuspid regurgitation and patent foramen ovale, consistent with a diagnosis of pulmonary hypertension.

The working diagnosis was a term infant with meconium aspiration syndrome and persistent pulmonary hypertension of the newborn (PPHN). The baby was intubated with mechanical ventilator support following no improvement after CPAP. Thermoregulation was maintained by infant warmer. Given fluid $80 \mathrm{cc} / \mathrm{kg}$ BW/day via an umbilical catheter. Empirical antibiotics were given with Ampicillin 50mg/kg BW twice daily and

\section{Figure 1: Chest x-ray taken 6 hours (Left) and 3 days (Right) after surfactant bolus administration}

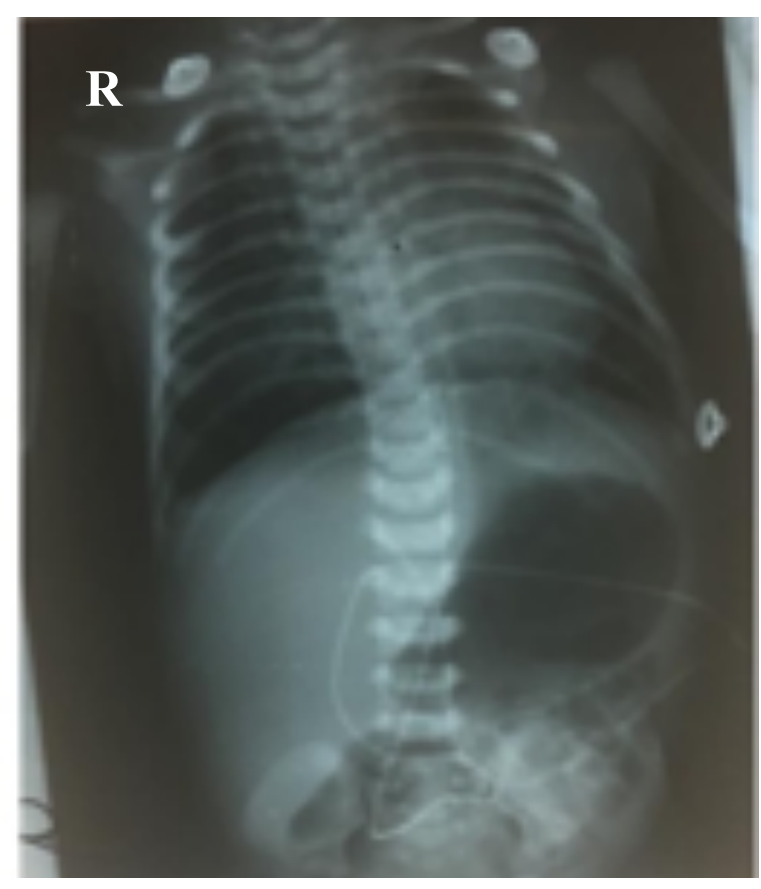


Gentamycin $5 \mathrm{mg} / \mathrm{kg}$ BW once daily. The PPHN therapy was treated with oral sildenafil $0.5 \mathrm{mg} /$ $\mathrm{kg}$ body weight (BW) four times a day, inotropic support by dobutamine equal to $5 \mathrm{mcg} / \mathrm{kg} /$ minute, and iloprost inhalation 2.5-5 mcg six times daily. At 21 hours after birth, the baby was worsened and got desaturated. The baby looked distressed with RR 70-80 breath per minute, SpO2 75-80\%, Temperature $(T)$ of 36,5 OC and we changed ventilator setting to PCV rate of 60 , Pcont of 20 , PEEP of $6, \mathrm{FiO} 2$ of $100 \%$. Sedation was controlled by morphine maintenance dose $10 \mathrm{mcg} / \mathrm{kg} / \mathrm{min}$. Bolus surfactant administration was instilled via an endotracheal tube with a dose of $100 \mathrm{mg} / \mathrm{kg}$ [4]. At 24 hours after the surfactant bolus, the baby was hemodynamically stable. Chest X-ray evaluation was performed and showed improvement (Figure 1). Eight days after surfactant administration, the baby can maintain good oxygenation without supplemental oxygen.

Case report 2: A baby girl born via spontaneous delivery. The gestational age was 38 weeks, the birth weight was 2600 grams, $49 \mathrm{~cm}$ in length, and $33 \mathrm{~cm}$ in head circumference. Skin, nails, and umbilical cord stained with greenish meconium. She wasn't crying after birth, grunting, and had poor muscle tone. The Apgar Score was 3 at one minute and 5 at five minutes. We did the initial step, including warm and maintaining normal temperature, airway position, tactile stimulation, suction, and repositioning. The maximum oxygen saturation was $74 \%$ at the tenth-minute room air. She received Neo T-CPAP with PEEP 8 and PIP 25 but was still lethargic and cyanotic. The maximum oxygen saturation reached was only $80 \%$.

Physical examination in NICU revealed a neonate with a weak cry with minimal grimacing to a painful stimulus, grunting, and cyanotic. Blood pressure (BP) was $65 / 35 \mathrm{mmHg}$, heart rate (HR) was 182 beats per minute, respiratory rate (RR) 64 breaths per minute with the temperature was $36,50 \mathrm{C}$, her pre-ductal saturation was $84 \%$ and post ductal saturation was $81 \%$. There was severe chest retraction and capillary refill time was less than 3 seconds. The Downes score was 8. Chest and abdominal X-Ray showed patchy infiltrates, consolidation at left hemithorax, area of hyperinflation and hypoinflation. Decreased expansion of the lung was indicated by diaphragm linear that appeared as high as chest rib 7th-8th. The working diagnosis was a term infant with meconium aspiration syndrome. The baby was admitted to NICU following no clinical improvement after initial resuscitation, intubated and mechanically ventilated. Blood gas analysis after intubation revealed metabolic acidosis with the value: $\mathrm{pH} 7.19, \mathrm{pCO} 248 \mathrm{mmHg}, \mathrm{pO} 2138$ $\mathrm{mmHg}, \mathrm{HCO} 318.3 \mathrm{mmol} / \mathrm{L}, \mathrm{TCO} 219.8 \mathrm{mmol} / \mathrm{L}$, $\mathrm{BE}-9.9 \mathrm{mmol} / \mathrm{L}, \mathrm{SO} 2 \mathrm{98} \%$. Thermoregulation was maintained by infant warmer. The baby was placed Nil Per Os, an umbilical catheter was inserted and he was given total parenteral nutrition of $60 \mathrm{cc} / \mathrm{kg}$ BW/day. Empirical antibiotics were given with Ampicillin 50mg/kg BW twice daily and Gentamycin 5mg/kg BW once daily. Inotropic support by dobutamine equal to $5 \mathrm{mcg} / \mathrm{kg} /$ minute was initiated and maintained for 24 hours. At 6 hours after birth, the baby was worsened and got desaturated with HR 176 bpm, RR $62 \mathrm{cpm}$, body temperature 37, and $\mathrm{SaO} 2$ 86\%. ABG revealed still metabolic acidosis with pH 7.19, pCO2 $61 \mathrm{mmHg}$, pO2 $61 \mathrm{mmHg}, \mathrm{HCO} 323.3 \mathrm{mmol} / \mathrm{L}$, TCO2 25.2 $\mathrm{mmol} / \mathrm{L}, \mathrm{BE}-4.9 \mathrm{mmol} / \mathrm{L}$, SO2 $88 \%$. Ventilator setting was changed to PCV, P control 15, PEEP 5, Pinsp 15, Rate 50, FiO2 90\% with oxygen saturation was $93 \%$. Inotropic support by dobutamine was increased equal to $10 \mathrm{mcg} / \mathrm{kg} /$ minute and dopamine equal to $5 \mathrm{mcg} / \mathrm{KgBW} /$ minute was added. Eight hours after birth, a bolus surfactant was instilled via an endotracheal tube with a dose of $100 \mathrm{mg} / \mathrm{kg}$ phospholipid (beractant). Chest x-ray monitoring was done (Figure 2).

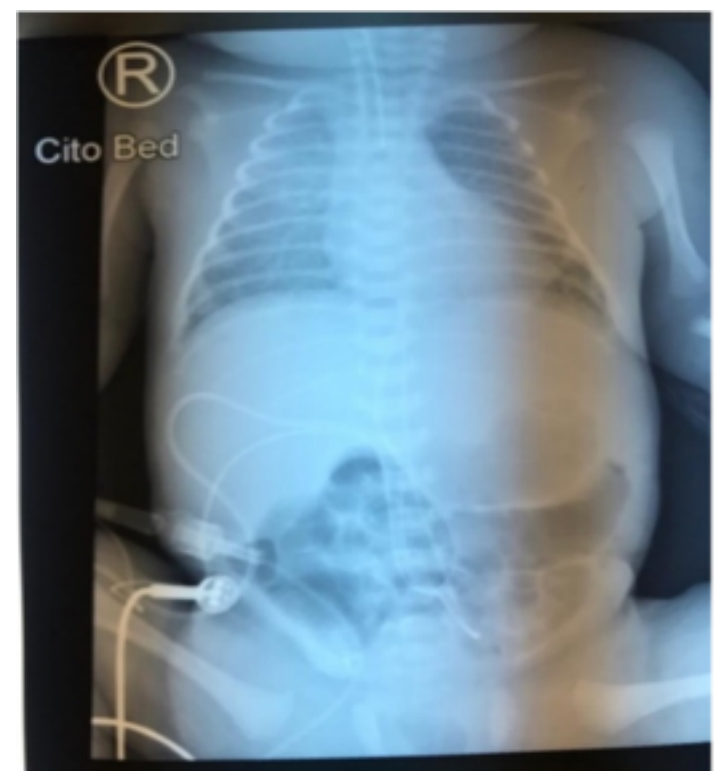

Figure 1: A chest x-ray taken 6 days after surfactant administration 
Table 1: Summary of clinical characteristics of the patients and maternal history

\begin{tabular}{lrr}
\hline Variables & Patient 1 & Patient 2 \\
\hline Mother's age & 25 & 35 \\
Gestational age & 38 weeks & 38 weeks \\
Apgar score (1 $\mathrm{min} / 5 \mathrm{~min})$ & $3 / 4$ & $3 / 5$ \\
Delivery mode & Cesarian section & Cesarian section
\end{tabular}

Endotracheal suction in the delivery

room

A day after surfactant administration, the baby was hemodynamically stable. Chest $x$-ray evaluation was taken 6 days after the surfactant bolus. ABG revealed pH 7.21, pCO2 $69 \mathrm{mmHg}, \mathrm{pO} 267$ $\mathrm{mmHg}, \mathrm{HCO} 227.6 \mathrm{mmol} / \mathrm{L}, \mathrm{TCO} 229.7 \mathrm{mmol} / \mathrm{L}$, BE - $0.3 \mathrm{mmol} / \mathrm{L}$, SO2 $93 \%$. On the 26th day, echocardiography was performed and revealed mild TR (max PG $17.9 \mathrm{mmHg}$ ). Advice from pediatric cardiology division dobutamine and dopamine was decreased gradually. The baby was extubated on the fourth day, replacing it with NIPPV. We then gradually changed her to CPAP, HFN (High Flow Nasal), then nasal cannulae. On the tenth day, the baby was weaned off O2. Descriptive data before and after surfactant administration are summarized in table 2.

\section{DISCUSSION}

Two distinct scenarios of MAS treated with surfactant therapy are described above. Both cases improved after surfactant administration, despite different clinical characteristics, treatment approaches, and outcomes. MAS primarily affects term and post-term infants and is extremely rare in preterm newborns. In this case, both were term infants. We diagnosed MAS by the following clinically-based findings: the first case showed evidence of meconium-stained MSAF, respiratory distress, and a chest $x$-ray showed an area of hyperinflation and hypoinflation. The second case chest $x$-ray revealed hyperinflation with patchy infiltrates. These findings suggest that MAS was the cause of respiratory distress in both cases. Arterial blood gas revealed metabolic acidosis in both our cases. Clinical characteristics of the patients and maternal history are summarized in table 1.

MAS is diagnosed by history taking, clinical course, and radiographic. Transient tachypnea of the newborn (TTN) is a frequent cause of respiratory distress in late preterm infants (34 to 37 weeks gestation). In contrast, MAS is most frequently seen in postmature infants ( $>41$ weeks' gestation)[5]. To define MAS severity, we use criteria by Cleary and Wisell: (1) mild, requiring < 40\% oxygen therapy for $<48$ hours; ( 2 ) moderate, requiring $\geq 40 \%$ oxygen therapy for at least 48 hours; (3) severe, requiring assisted mechanical ventilation for more than 48 hours and is often associated with PPHN [6]. In this case, all infant oxygenation was given with $\mathrm{FiO} 2>$ $40 \%$ more than 48 hours. So, it can be categorized as severe MAS.

Surfactant replacement therapy has recently emerged as rescue therapy in MAS, which has the advantage of decreasing morbidity and 
Table 2: Descriptive data before and after surfactant administration of the $\mathbf{2}$ cases

\begin{tabular}{lrr}
\hline & Patient 1 & Patient $\mathbf{2}$ \\
\hline Age on arrival (hour) & 8 & 0 \\
Time of administration & 23 hours after birth & 8 hours after birth \\
Surfactant doses & $100 \mathrm{mg} / \mathrm{kg} \mathrm{BW}$ & $100 \mathrm{mg} / \mathrm{kg} \mathrm{BW}$ \\
& & Phospholipid \\
Types of surfactant & Natural & Natural
\end{tabular}

\section{Clinical and laboratory characteristics before}

surfactant bolus:

$-\quad$ Ol

- $\mathrm{A}-\mathrm{aDO} \mathrm{O}_{2}$

- Blood pressure

- HR

- $\quad R R$

\section{4 hours after bolus}

$$
\begin{array}{ll}
- & \mathrm{Ol} \\
- & \mathrm{A}-\mathrm{aDO}_{2} \\
- & \text { Blood pressure } \\
- & \mathrm{HR} \\
- & \mathrm{RR}
\end{array}
$$

OI: Oxygenation Index, HR: Heart Rate, RR: Respiratory Rate, A-aDO2: Alveolar-Arterial Oxygen Gradient, PPHN: Persistent Pulmonary Hypertension of the Newborn

mortality[7,8]. In vitro studies have shown that meconium interferes with surfactant in several ways: inactivation of its function depending on the concentration, direct toxicity on type II pneumocytes, displacement of surfactant from the alveolar surface, and decrease of surfactant protein A and B levels [9]. A systematic review by Natarajan et al. stated surfactant therapy in neonates with MAS either as bolus or lavage was found to reduce the duration of mechanical ventilation and hospital stay [10].
Survanta (Beractant) is a natural surfactant and the only available option in our hospital pharmaceutical formulary. A recent study by Singh et al. revealed no statistically significant differences in the results achieved after administrations of natural and synthetic surfactant [11]. Based on clinical criteria, a total of $100 \mathrm{mg} / \mathrm{kg}$ BW phospholipid surfactant bolus was used in both cases. This amount was based on the suggestion of Dargaville et al. and the clinical outcomes of our cases were excellent [3]. In our first case, the oxygen index (OI) was 
34.4 and the alveolar-arterial oxygen gradient (AaDO2) revealed 619, while in our second case, $\mathrm{Ol}$ revealed 39 and $\mathrm{AaDO} 2$ 457. Clinical improvement 24 hours after surfactant bolus administration was seen in this case series. Ozge et al. also defined other criteria for surfactant administration in the newborn: the need for mechanical ventilation with a FiO2 $>0.5$, Mean airway Pressure (MAP) $\geq$ $7 \mathrm{~cm} \mathrm{H} 2 \mathrm{O}, \mathrm{OI} \geq 15$, and/or abnormal arterial blood gas analysis showing hypoxia $(\mathrm{PaO} 2<50 \mathrm{mmHg}$ ), hypercapnia (PaCO2> $50 \mathrm{mmHg}$ ) or acidosis $(\mathrm{pH}<7.2)$ combined with radiological evidence of pulmonary disease on the chest X-ray. Both newborns in our case series meet these criteria $[3,12]$.

The first baby was given surfactant at 23 hours after birth due to an insurance issue and the second baby at 8 hours after birth. Failing to administer surfactant early will reduce its effectiveness by inflammatory and chemical changes induced by meconium aspiration gradually increased over time after birth. It is doubtful whether there is much benefit gained by surfactant administration after 24 hours [3]. Research by Dargaville et al. in 2011 showed a lack of effectiveness when administered 14 hours after birth [12]. Old data in 1997 demonstrated on a model of MAS piglet, inflammatory indicator peaks between 12- 24 hours [13]. A recent study revealed that surfactant should be given before 6 hours to have a beneficial effect [3]. The first case showed better clinical outcomes immediately after surfactant administration, while the second case did not. We assumed the underlying pulmonary pathology was more severe in the first case. PPHN was not confirmed in our second case because echocardiography was not performed immediately after birth. Initial chest $x$-ray in our second case showed infiltrates, while in the first case, it did not. In the first case, the administration of surfactant bolus followed by iloprost and sildenafil had a positive influence on the improvement in oxygenation. Sildenafil oral was given $1.5 \mathrm{mg}$ four times daily. Sahl and Olson conducted Cochran analysis on the effectiveness of sildenafil for PPHN infants and concluded that sildenafil could reduce mortality, and improve oxygenation in infants with

\section{REFERENCES}

1. T. F. Yeh, "Core Concepts: Meconium Aspiration Syndrome: Pathogenesis and Current Management," NeoReviews, vol. 11, no. 9, pp. 503-512, Sep. 2010.
PPHN [13]. Iloprost inhalation was given 2.5-5 mcg 6 times daily. Kim et al. concluded that inhaled iloprost could be used as an alternative treatment of PPHN without side effects of systemic hypotension when inhaled nitric oxide is not available [14]. The first baby was hemodynamically unstable, making it a high risk the side effects like hypotension due to systemic vasodilation was high. Therefore, inhaled iloprost was preferred over systemic vasodilators. Both our babies were given an inotropic agent. The first baby was started on dobutamine at a dose of $5 \mathrm{mcg} / \mathrm{kg} / \mathrm{minute}$, whereas dopamine was given to the second baby as combination therapy with dobutamine. Systemic blood pressure should be maintained at normal values for gestational age [15]. All of our cases used ampicillin and gentamycin as first-line broad-spectrum antibiotics. Meconium is sterile, but it still can inhibit the bacteriostatic function of the amniotic fluid. It is also difficult to differentiate meconium aspiration from pneumonia radiographically since both show the same infiltrate appearance on chest $\mathrm{x}$-ray. For that cause, an early broad-spectrum antibiotic should be started after the culture is obtained. In both cases, the bacterial culture was sterile. [16]. Many points lack in management of this case. We failed to perform surfactant administration early in both cases, where a recent study recommended less than 6 hours. We were also unable to perform early echocardiography to assess PPHN.

\section{CONCLUSION}

In conclusion, treatment success relied on the timing of surfactant administration and the degree of illness of the neonates. A detailed evaluation of underlying pulmonary pathology and its complication before surfactant administration is crucial to determine the therapy outcome. The relative efficacy of surfactant therapy compared to, or in conjunction with, other treatment approaches, including inhaled nitric oxide, liquid ventilation, surfactant lavage, and high-frequency ventilation, remains to be tested in more limited performance settings in a developing country.

2. Neonatology Division Department of Child Health Dr. Soetomo General Hospital Surabaya, "The Top 10 Causes Of Neonatal Death Reported From January to November 2014," RSUD dr Soetomo, 2014.

3. P. H. Haakonsen Lindenskov, A. Castellheim, O. 
D. Saugstad, and T. E. Mollnes, "Meconium Aspiration Syndrome: Possible Pathophysiological Mechanisms and Future Potential Therapies," Neonatology, vol. 107, no. 3, pp. 225-230, Feb. 2015.

4. P. A. Dargaville and J. F. Mills, "Surfactant Therapy for Meconium Aspiration Syndrome," Drugs, vol. 65, no. 18, pp. 2569-2591, 2005.

5. A. Goel and S. Nangia, "Meconium Aspiration Syndrome: Challenges And Solutions," Research and Reports in Neonatology, vol. Volume 7, pp. 19-28, Aug. 2017.

6. Goel and S. Nangia, "Meconium aspiration syndrome: challenges and solutions," Research and Reports in Neonatology, vol. Volume 7, pp. 19-28, Aug. 2017.

7. El Shahed A, Dargaville P, Ohlsson A, Soll R. Surfactant For Meconium Aspiration Syndrome in Term and Late Preterm Infants. Cochrane Database of Systematic Reviews. 2014;(12):1-2. doi: 10.1002/14651858.CD002054.pub3.

8. El Shahed Al, Dargaville P, Ohlsson A, Soll RF. Surfactant For Meconium Aspiration Syndrome In Full Term/Near Term Infants. Cochrane Database Syst Rev. 2007 Jul 18;(3):CD002054. doi: 10.1002/14651858. CD002054.pub2.

9. K. Swarnam, A. S. Soraisham, and S. Sivanandan, "Advances in the Management of Meconium Aspiration Syndrome," International Journal of Pediatrics, vol. 2012, pp. 1-7, Jan. 2012.

10. C. K. Natarajan, M. J. Sankar, K. Jain, R. Agarwal, and V. K. Paul, "Surfactant Therapy And Antibiotics In Neonates With Meconium Aspiration Syndrome: A Systematic Review And Meta-Analysis," Journal of Perinatology, vol. 36, no. S1, pp. 49-54, May 2016.

11. G. W. Jeon, "Surfactant Preparations For Preterm Infants With Respiratory Distress Syndrome: Past, Present, and Future," Korean Journal of Pediatrics, vol. 62, no. 5, pp. 155-161, May 2019.

12. Sürmeli-onay Ö, Korkmaz A, and Yiğit S, Yurdakök M, "A Retrospective Evaluation of Term Infants Treated With Surfactant Therapy," Journal of Pediatric and Neonatal Individualized Medicine, vol. 4, no. 1, pp. $1-7,2015$.

13. Gauchan E, Basnet S, and Malla T, "Meconium Aspiration Syndrome and Neonatal Outcome: A Prospective Study," American Journal of Public Health, vol. 3, no. 5a, pp. 48-52, 2015.

14. S. H. Kim, H. J. Lee, N. S. Kim, and H.-K. Park, "Inhaled Iloprost as A First-Line Therapy for Persistent Pulmonary Hypertension of The Newborn," Neonatal Medicine, vol. 26, no. 4, pp. 191-197, Nov. 2019.

15. J. Nair and S. Lakshminrusimha, "Update on PPHN: Mechanisms and Treatment," Semin Perinatol, vol. 38, no. 2, pp. 78-91, Mar. 2014.

16. P. H. Haakonsen Lindenskov, A. Castellheim, O. D. Saugstad, and T. E. Mollnes, "Meconium Aspiration Syndrome: Possible Pathophysiological Mechanisms and Future Potential Therapies," Neonatology, vol. 107, no. 3, pp. 225-230, 2015. 